Л И ТЕ Р А Т У Р А

1. С моляк С. А., Об оптимальном восстановлении функций и функционалов от них, Канд. дисс., М., 1965.

2. Бах валов Н. С., ЖВМ и МФ., 11, 1014 (1971).

3. Л е в н М., Изв. АН ЭССР, Физ. Матем., 20, 90 (1971).

4. Л е в и М., Изв. АН ЭССР, Физ. Матем., 23, 179 (1974)

5. Л е в и М., Изв. АН ЭССР, Физ. Матем., 12, 44 (1963).

6. Л в и н М., Изв. АН ЭССР, Физ. Матем., 12, 376 (1963).

7. Л е в и н М., Тр. Таллинск. политехн. ин-та, Сер. А, № 222, 14 (1965),

Софийский государственный университет

Поступнла в редакцию $8 / \mathrm{X} \quad 1975$

EESTI NSV TEADUSTE AKADEEMIA TOIMETISED. 25. KOIDE FOOSIKA * MATEMAATIKA, 1976, NR. 2

ИЗВЕСТИЯ АКАДЕМИИ НАУК ЭСТОНСКОИ ССР. ТОМ 25 ФИЗИКА * МАТЕМАТИКА. 1976; № 2

удК 681.327 .6

Х. ВАЛЛАСТЕ

\title{
ОБ ИЗМЕРЕНИИ ДИФФЕРЕНЦИАЛЬНОЙ МАГНИТНОЙ ВОСПРИИМЧИВОСТИ ЦТМП
}

H. VALLASTE. OHUKESTE SILINDRILISTE MAGNETKILEDE DIFERENTSIAALSE MAGNETILISE VASTUVOTLIKKUSE UURIMINE

H. VALLASTE, A STUDY OF DIFFERENTIAL MAGNETIC SUSCEPTIBILITY OF PLATED WIRE

Для экспериментального изучения дифференциальной магнитной восприимчивости цилиндрических тонких магнитных пленок (ЦТМП) в зависимости от поля смещения автором была собрана установка, позволяющая записывать на двухкоординатном самописце кривые восприимчивости при квазистатическом перемагничивании пленок по оси легкого намагничивания (ОЛН) или по оси трудного намагничивания (OTH). Блок-схема установки показана на рис. 1. Источником тока перемагничивания служит специально изготовленный генератор линейно изменяющегося по времени тока с максимальной амплитудой 0,5 a и скоростью нарастания тока 1 а/мин. Для предварительного насыщения ЦТМП используется отдельный источник импульсов тока с амплитудой до $15 a$ и длительностью 0,2 сек. Для получения сигнала, пропорционального дифференциальной восприимчивости ЦТМП, образцы возбуждаются слабым переменным магнитным полем с частотой 175 кец и амплитудой $H_{\sim}<10^{-3}$ э. Допустимое максимальное значение этого поля определяется по исчезновению мнимой (гистерезисной) составляющей восприимчивасти. Сигнал с образцов проходит через настроенный дифференциальный предусилитель и селективный вольтметр В6-2, после чего поступает на вход стробирующей приставки C1-21. Последняя запускается от генератора ГЗ-33, служащего источником тока возбуждения. Выбором момента стробирования можно на выходе приставки получать сигнал, соответствующий действительной или мнимой составляющей восприимчивости. Приставка усовершенствована так, что к ее выходу можно непосредственно подключать канал 
Рис. 1. Блок-схема установки: 1 - образец, 2 - подложка без пленки, 3 - генератор Г3-33, 4 - генератор тока перемагничнвания.

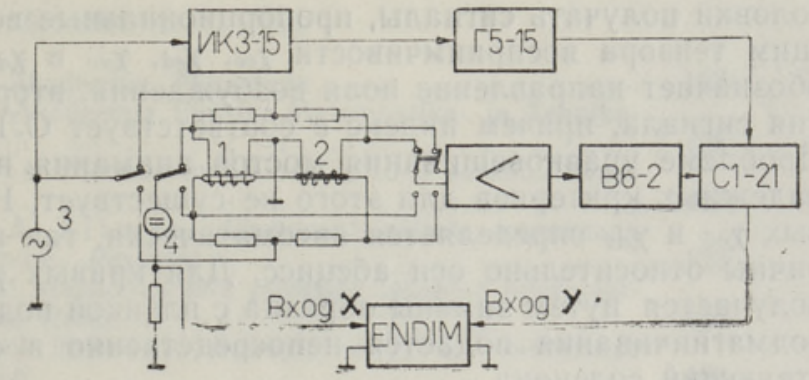

вертикального отклонения самописца ENDIM-2200. Кроме того, в нее введена дополнительная обратная связь, обеспечивающая линейность усиления лучше $0,5 \%$ при амплитуде входного сигнала в пределах 58 . Для обеспечения такой же линейности переделан вольтметр В6-2. На канал горизонтальной развертки самописца подается напряжение с резистора в цепи тока перемагничивания. Линейность всего тракта усиления в рабочем диапазоне не хуже $1 \%$.

В качестве измерительной головки использовалась мостовая схема, состоящая из двух резисторов по 100 ом и двух однослойных соленоидов с числом витков 80 , длиной 27 мм и диаметром отверстия 0,7 мм. Внутрь одного соленоида помещается образец, внутрь другого - проволочная подложка без пленки. На одну диагональ моста подается переменный ток возбуждения, с другого снимается сигнал. Этот мост позволяет возбуждать пленку по ОТН и по ней же измерять изменение проекции намагниченности. Для возбуждения и измерения по ОЛН в измерительной головке есть второй мост, аналогичный первому, причем в качестве двух плечей используется тот же образец и та же проволочная подложка. Переключением двух тумблеров можно на выходе

Рис. 2. Кривые восприимчивости:

$h_{x}=\frac{H_{x}}{H_{k}}, \quad h_{y}=\frac{H_{y}}{H_{k}}$
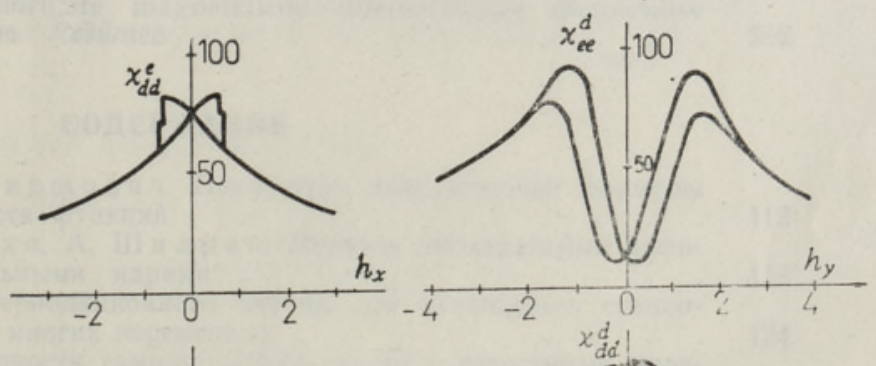

$\left(H_{x}\right.$ - по ОЛН, $H_{y}-$ по ОТН).
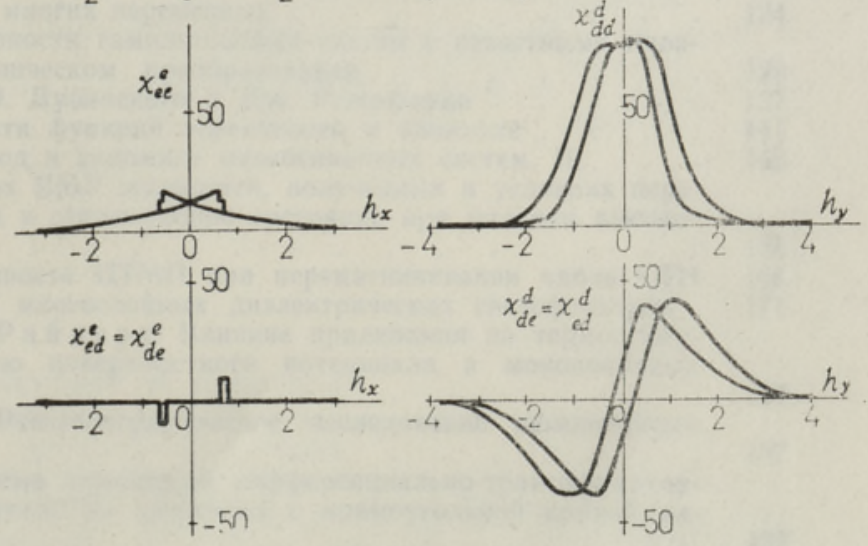
головки получать сигналы, пропорциональные всем четырем составляющим тензора восприимчивости $\chi_{e e}, \chi_{e d}, \chi_{d e}$ и $\chi_{d d}$. Здесь первый индекс обозначает направление поля возбуждения, второй - направление снятия сигнала, причем индекс $e$ соответствует ОЛН, а индекс $d-$ OTH. Проблеме уравновешивания мостов внимания не уделялось, поскольку надежных критериев для этого не существует. Нулевая линия для кривых $\chi_{e d}$ и $\chi_{d e}$ определяется автоматически, так как эти кривые симметричны относительно оси абсцисс. Для кривых $\chi_{e e}$ и $\chi_{d d}$ нулевая линия получается путем замены образца с пленкой подложкой без пленки. Ток подмагничивания подается непосредственно в образец или в соответствующий соленоид.

Для настройки установки используется осциллограф с двухканальным коммутатором, позволяющим наблюдать форму сигнала и фазовые соотношения между сигналом и возбуждающим полем.

Проведена калибровка осей абсцисс и ординат в абсолютных единицах на основе геометрических и магнитных расчетов. В качестве примера на рис. 2 приведены кривые восприимчивости при перемагничивании вдоль ОЛН $\left(\chi^{e}\right)$ и ОТН $\left(\chi^{d}\right)$ ЦТМП с неразрушающим считыванием, для которой $H_{k}=4,6$ э, $H_{c}=2,6$ э, $H_{c}^{d}=0,75$ э. Пленка осаждена на шероховатую подложку из бериллиевой бронзы диаметром 0,15 мм, толщина пленки 0,8 мкм.

Ннститут кибернетики Академии наук Эстонской ССР
Поступнла в редакцию 17/XI 1975 